\title{
ELETRÓLISE DE RESÍDUOS POLUIDORES. I - EFLUENTE DE UMA INDÚSTRIA LIOFILIZADORA DE CONDIMENTOS
}

\author{
Dejanira F. de Angelis, Carlos R. Corso e Ederio D. Bidoia \\ Departamento de Bioquímica e Microbiologia - Instituto de Biociências - UNESP - Universidade Estadual Paulista "Júlio de \\ Mesquita Filho" - 13506-900 - Rio Claro - SP \\ Peterson B. Moraes e Roberto N. Domingos \\ Departamento de Física - Instituto de Geociências e Ciências Exatas - UNESP - Universidade Estadual Paulista "Júlio de Mesquita \\ Filho" - 13500-230 - Rio Claro - SP \\ Romeu C. Rocha-Filho \\ Departamento de Química - UFSCar - Universidade Federal de São Carlos - 13565-905 - São Carlos - SP
}

Recebido em 12/12/96; aceito em 21/5/97

\begin{abstract}
ELECTROLYSIS OF POLLUTING WASTES. I - WASTEWATER FROM A SEASONING FREEZE-DRYING INDUSTRY. Wastewater from a seasoning freeze-drying industry was electrolysed to increase its biodegradability. Stainless-steel electrodes were used at $9.09 \mathrm{~A} / \mathrm{m}^{2}$, for up to 80 min. Conductivity, pH, biochemical (BOD) and chemical (COD) oxygen demands, Daphnia similis acute toxicity bioassays, and bacteria counting through the plate count agar method were determined after different times of electrolysis. The results $(e . g$. higher BOD and lower COD) showed that the biodegradability of the wastewater was significantly increased; furthermore, $\mathrm{Fe}^{2+}$ ions liberated by the electrodes cause microorganisms to die and, when oxidised to $\mathrm{Fe}^{3+}$, contribute for the flocculation and sedimentation of solid residues.
\end{abstract}

Keywords: electrolysis; seasoning wastewater; wastewater treatment.

\section{INTRODUÇÃO}

O simples ato de viver implica que seres humanos gerarão resíduos ( $2^{\mathrm{a}}$ lei da Termodinâmica). Isto sempre foi verdade, mas só mais recentemente passou a causar problemas. Anteriormente o processo de tratamento de resíduos da própria natureza (dispersão, diluição e degradação) garantia que o equilíbrio natural não fosse alterado. Mais modernamente, em decorrência de mudanças tanto qualitativas quanto quantitativas nos resíduos gerados, a situação deixou de ser tão simples. Muitos materiais modernos (plásticos, substâncias agroquímicas etc.) não degradam facilmente e a taxa de geração de resíduos é hoje muito maior que a de sua degradação natural. Assim, não resta outra alternativa a não ser minimizar a entrada de resíduos na atmosfera, na hidrosfera e na litosfera, bem como minimizar a geração de resíduos sólidos. Para evitar que resíduos poluidores adentrem o ambiente, eles devem ser purificados a ponto de permitir que a natureza tome conta do resto: este é o problema de tratamento de resíduos ${ }^{1}$, no que se insere este artigo. A Eletroquímica pode contribuir muito para a solução deste problema ${ }^{1-4}$, seja por si só ou acoplada aos métodos biológicos, como discutido abaixo. Entre as características que tornam atrativo o tratamento eletroquímico, destacam-se ${ }^{3}$ : versatilidade, eficiência de energia, facilidade de automação, compatibilidade ambiental e baixo custo efetivo.

Águas industriais poluídas por compostos orgânicos são tratadas, mais comumente, através de sistemas biológicos, amplamente utilizados para o tratamento de efluentes lançados nos sistemas fluviais e marinhos. O tratamento biológico possui, entretanto, algumas desvantagens que levam à investigação de novos métodos ou, até mesmo, ao desenvolvimento de tratamentos alternativos. Entre as desvantagens destacam-se a grande área ocupada pelos sistemas convencionais de tratamento biológico (várias lagoas aeróbias, anaeróbias e facultativas), a exalação de odores desagradáveis e sua total inutilidade no caso da presença de alguns resíduos que contêm substâncias tóxicas ao processo (pouco biodegradáveis ou não biodegradáveis).
Assim, a eletrooxidação de compostos orgânicos pode ter o objetivo de servir como um pré-tratamento de compostos tóxicos e não biodegradáveis para que estes sejam posteriormente tratados através de sistemas biológicos convencionais. O esquema de tratamento pode ser representado simplificadamente pela sequência dada abaixo:

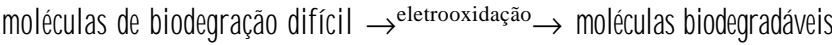

moléculas biodegradáveis $\rightarrow^{\text {tratamento biológico }} \rightarrow \mathrm{CO}_{2}+\mathrm{H}_{2} \mathrm{O}+$ sais + energia

Materiais não biodegradáveis são, em geral, compostos contendo anéis aromáticos ou polímeros sintéticos, cuja eletrooxidação faz com que se transformem em moléculas biodegradáveis ${ }^{5}$.

As eletrólises de águas residuais podem ser utilizadas também para a transformação total das moléculas orgânicas em gás carbônico e água, servindo como um tratamento alternativo ao tratamento biológico ${ }^{6}$, sendo então conhecido como incineração eletroquímica ${ }^{7}$. Para chegar a este nível de oxidação, é necessário o uso de fortes agentes oxidantes gerados eletroquimicamente, que convertem os poluentes a produtos menos danosos. Um exemplo é a geração eletrolítica de íons fortemente oxidantes, como prata (II $)^{6}$, que oxidariam as moléculas orgânicas, sendo posteriormente regenerados eletroliticamente. Este método indireto tem sido pouco usado devido à alta concentração de matéria orgânica nos efluentes urbanos e industriais; a sua total eletrooxidação a gás carbônico e água acarretaria num gasto elevado de energia elétrica, o que torna-a financeiramente proibitiva. Por outro lado, a inclusão de íons oxidantes nas águas residuais implica na necessidade de retirá-los do efluente após o tratamento, adicionando mais uma etapa ao processo, ou seja, custos extras. Uma alternativa é o uso de materiais de eletrodo que favoreçam a combustão eletroquímica da matéria orgânica; segundo Comninellis ${ }^{5}$, estes eletrodos são os que acumulam radicais ${ }^{\circ} \mathrm{OH}$ (oxigênio ativo fisisorvido) em suas superfícies.

Eletrólises de efluentes brutos, também chamadas de processo eletrolítico ${ }^{8}$, foram aplicadas para o tratamento de 
esgostos urbanos no Estado de São Paulo na década ${ }^{9}$ de 80. Entretanto, o resultado deste tratamento foi questionado pela CETESB - Companhia de Tecnologia de Saneamento Ambiental ${ }^{10}$, tendo sido apontada ineficiência das eletrólises em reduzir a matéria orgânica aos níveis permitidos pela legislação vigente. À posição da CETESB pode-se contra-argumentar que a manutenção da infra-estrutura utilizada no sistema de eletrólises fora descuidada; assim, os laudos técnicos negativos dados pela CETESB em relação ao processo eletrolítico foram decorrência mais da falta de manutenção do que propriamente da metodologia aplicada.

Em comparação aos métodos biológicos de tratamento, as vantagens do processo eletrolítico são a pequena área requerida, a inexistência ou pouca incidência de odores fortes, a não necessidade de adição de produtos químicos durante o tratamento, os tempos curtos de detenção do efluente e a fácil automatização. Poder-se-ía dizer que a eletrólise é um processo ecologicamente "limpo".

Estudos preliminares com resíduo (efluente líquido) de uma indústria liofilizadora de condimentos (cebola, alho, pimentão etc.) para a indústria alimentícia, localizada em Rio Claro $\mathrm{SP}$, indicaram que esse resíduo apresentava baixa biodegradabilidade. Imediatamente, pensou-se na eventual possibilidade de aumentar a biodegradabilidade desse resíduo através da sua eletrólise. Este trabalho relata os resultados obtidos.

\section{BREVE REVISÃO HISTÓRICA DO PROCESSO ELETROLÍTICO}

Esta revisão histórica visa dar uma idéia sobre quando o processo eletrolítico surgiu e sobre o seu uso no Brasil. A primeira menção do uso de eletrólise para o tratamento de efluentes data de 1887, quando Eugene Hermite patenteou um processo de tratamento. Este consistia na mistura de água do mar com o esgoto bruto e na eletrólise da mistura para produzir cloro no anodo, que por sua vez atuava como agente oxidante e bactericida ${ }^{11}$. No catodo, o hidróxido de magnésio produzido pela eletrólise funcionava como agente floculante. As instalações do processo Hermite, construídas na Inglaterra e França durante a década de 1890, foram posteriormente desativadas por serem consideradas economicamente inviáveis.

Em Crossness, subúrbio de Londres, William Webster testou um processo eletrolítico usando eletrodos de ferro, tendo observado que hidróxido de ferro era formado com conseqüente precipitação de corpo de fundo e com a desodorização do líquido sobrenadante ${ }^{12}$. Este processo ficou conhecido como processo Webster e é aplicável especialmente em cidades litorâneas.

Saturnino de Brito, em 1943, estudou e testou no Brasil, após ter conhecimento das instalações de tratamento em Santa Mônica, Califórnia, nos Estados Unidos ${ }^{13}$ (também existiram instalações em diversas outras cidades americanas ${ }^{1}$ ). Em 1985, Wiendl ${ }^{14}$ retomou o uso do processo eletrolítico no Brasil, ao implantar uma estação de tratamento em Iracemápolis - SP. Nos anos seguintes, outras estações de tratamento utilizando o processo eletrolítico foram instaladas nos municípios de Limeira, Pirassununga, Marília, Campinas e Águas de Lindóia, no Estado de São Paulo. Conforme já mencionado, em 1989, a CETESB divulgou um relatório ${ }^{10}$, no qual concluía que o processo eletrolítico não era viável devido principalmente a:

a) a operação do sistema vinha demonstrando que, em decorrência de variações das características do efluente a ser tratado, era quase impossível controlar, de forma econômica, as variações elétricas para manter o desempenho do tratamento dentro de parâmetros preconizados;

b) a duração dos eletrodos era, no máximo, de 7 meses;

c) todos os sistemas experimentais eram de pequena capacidade e o processo eletrolítico não saira do estágio de investigação em planta piloto; d) o lodo resultante do processo não apresentava-se estabilizado e exalava maus odores.

Após o relatório da CETESB, as instalações nas cidades acima citadas foram gradativamente abandonadas.

Apesar disso, o tratamento de efluentes por eletrólise está sendo utilizado em muitas empresas e em recuperação ambiental $^{2-5,15-18}$, podendo-se constatar que as características da instalação (eletrodos, corrente ou potencial aplicado, fluxo de efluente, etc.) devem ser adaptadas para cada caso e tipo de efluente. Um tratamento eletrolítico que sirva para todos os tipos de efluente ou para efluentes misturados, como os provenientes de áreas urbanas, parece ser ainda um objetivo bem distante. Entretanto, o estudo dos efeitos da eletrólise de efluentes tem sido um campo de pesquisa cada vez mais explorado $3,4,18-24$.

\section{PROCEDIMENTO EXPERIMENTAL}

O sistema de eletrodos utilizado, do tipo colméia (diversos eletrodos posicionados paralelamente), é mostrado na figura 1 . Esse sistema de eletrodos foi construído com 14 placas intercaladas de aço inoxidável 304 , de $1 \mathrm{~mm}$ de espessura, cada uma de área facial de $314 \mathrm{~cm}^{2}$ e distantes $5 \mathrm{~mm}$ entre si. A área total anódica da colméia era, portanto, de $0,44 \mathrm{~m}^{2}$. As eletrólises foram realizadas em volumes iniciais de $8,6 \mathrm{~L}$ de efluente bruto (como coletado), o qual era vigorosamente agitado através de agitador de hélice. Após tempos pré-determinados de eletrólise, esta era suspensa e amostras do efluente eletrolisado eram recolhidas; a seguir, se fosse o caso, a eletrólise era reiniciada. Utilizou-se uma fonte de corrente contínua Fok Gyem, modelo TR-9158/A (40V, 10A). As medidas de condutividade foram realizadas com condutivímetro Tecnopom, modelo CA150.

O efluente eletrolisado era o resíduo, de difícil biodegradação, de uma indústria liofilizadora de condimentos (condimentos liofilizados, óleos e águas de lavagens de máquinas).

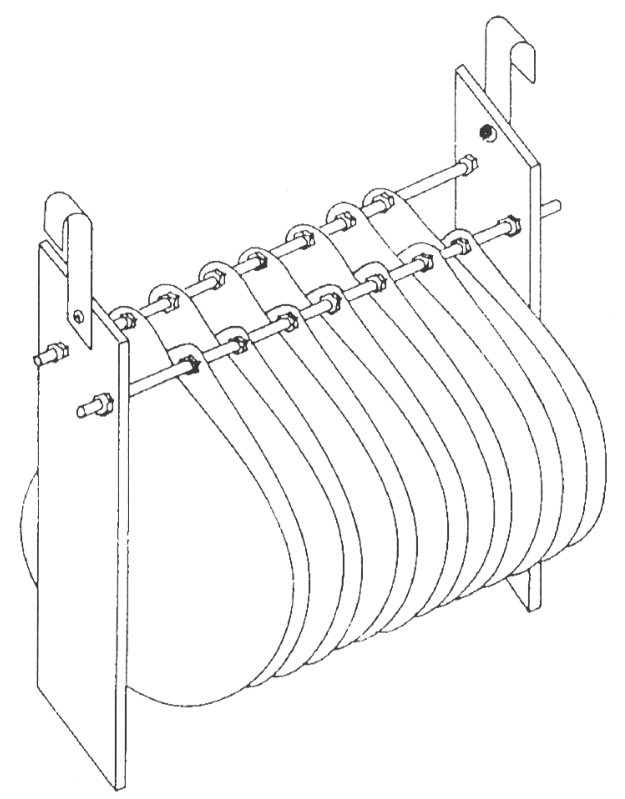

Figura 1. Conjunto de eletrodos de placas intercaladas de aço inoxidável (montagem tipo colméia).

As eletrólises foram realizadas galvanostaticamente $(4,00 \mathrm{~A}$, ou seja, 9,09 $\mathrm{A} \mathrm{m}^{-2}$ ), por até $80 \mathrm{~min}$, sendo que o potencial variou de $2,0 \mathrm{~V}$ a $3,5 \mathrm{~V}$. As amostras coletadas após diferentes tempos de eletrólise tiveram sua condutividade e seu $\mathrm{pH}$ medidos e foram submetidas às seguintes análises ${ }^{25}$ : 
a) demanda química de oxigênio (DQO);

b) demanda bioquímica de oxigênio (DBO);

c) sólidos sedimentáveis;

d) biotoxicidade aguda utilizando Daphnia similis;

e) contagem microbiana através do método "pour plate" empregando o meio de cultivo "plate count agar" (PCA).

\section{RESULTADOS E DISCUSSÃO}

A figura 2 mostra como o $\mathrm{pH}$ do efluente variou com o tempo de eletrólise. Após $80 \mathrm{~min}$, seu valor aumentou de cerca 5 para cerca de 8 . Esse aumento pode ser atribuído ao consumo de $\mathrm{H}^{+}$decorrente da formação de hidrogênio no catodo:

$2 \mathrm{H}^{+}(\mathrm{aq})+2 \mathrm{e}^{-} \rightarrow \mathrm{H}_{2}(\mathrm{~g})$

Por sua vez a redução de água no catodo pode levar a um aumento da quantidade de $\mathrm{OH}^{-}$, também contribuindo para aumentar o $\mathrm{pH}$ :

$2 \mathrm{H}_{2} \mathrm{O}(\mathrm{l})+2 \mathrm{e}^{-} \rightarrow \mathrm{H}_{2}(\mathrm{~g})+2 \mathrm{OH}^{-}(\mathrm{aq})$

Já no anodo há várias reações ocorrendo. Além da oxidação da matéria orgânica, a formação de íons $\mathrm{Fe}^{2+}$ e a oxidação de moléculas de água:

matéria orgânica $\rightarrow$ matéria orgânica oxidada + ne

$\mathrm{Fe}(\mathrm{s}) \rightarrow \mathrm{Fe}^{2+}(\mathrm{aq})+2 \mathrm{e}^{-}$

$2 \mathrm{H}_{2} \mathrm{O}(\mathrm{l}) \rightarrow \mathrm{O}_{2}(\mathrm{~g})+4 \mathrm{H}^{+}(\mathrm{aq})+4 \mathrm{e}^{-}$

Conforme mostra a equação (5), a oxidação da água leva à formação de $\mathrm{H}^{+}(\mathrm{aq})$ no anodo. Entretanto, o consumo desse íon no catodo prevalece em relação à sua formação no anodo, visto que as reações representadas nas equações (3) e (4) ocorrem predominantemente. Assim, haverá aumento dos valores de $\mathrm{pH}$ devido à diminuição da concentração de íons $\mathrm{H}^{+}(\mathrm{aq})$ e a formação de íons $\mathrm{OH}^{-}(\mathrm{aq})$ com o decorrer da eletrólise. A formação de íons $\mathrm{Fe}^{2+}(\mathrm{aq})$ e sua posterior oxidação para $\mathrm{Fe}^{3+}(\mathrm{aq})$ leva à precipitação do hidróxido de ferro (III), de cor avermelhada; cabe ressaltar que essa oxidação pelo oxigênio torna-se mais rápida à medida que o meio se torna básico.

Relações complexas que favorecem ou não o aumento dos valores de $\mathrm{pH}$ podem ocorrer. No entanto, na maioria dos resíduos eletrolisados descritos em trabalhos prévios ${ }^{26,27}$ houve tendência de elevação dos valores de $\mathrm{pH}$, mesmo que de forma suave, constatando-se assim o decréscimo da concentração de $\mathrm{H}^{+}$com o prolongamento do tempo de eletrólise para diferentes resíduos.

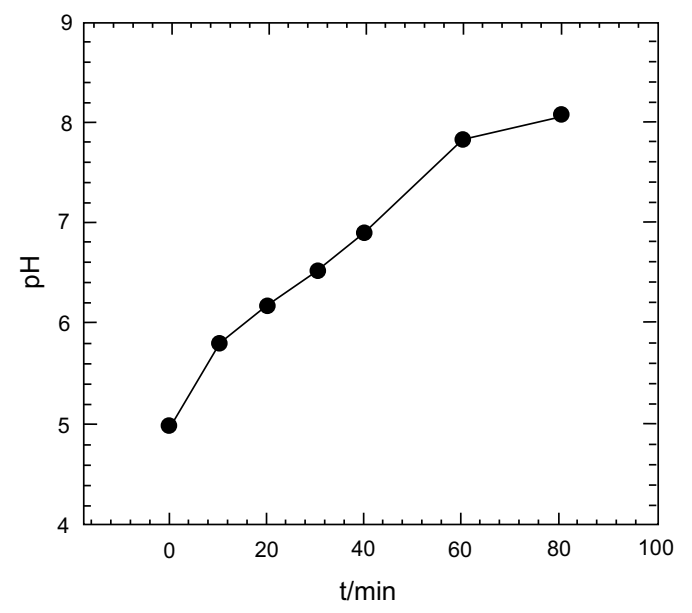

Figura 2. Variação do pH em função do tempo de eletrólise de um efluente de uma indústria liofilizadora de condimentos.
Durante a eletrólise, a temperatura do efluente eletrolisado não variou, mantendo-se em $20^{\circ} \mathrm{C} \pm 1{ }^{\circ} \mathrm{C}$. Já a sua condutividade aumentou com o tempo de eletrólise (vide Fig. 3). Isto pode ser atribuído principalmente ao aumento dos íons presentes, qual seja a formação de íons ferro (II) ou de íons provenientes de matéria orgânica oxidada.

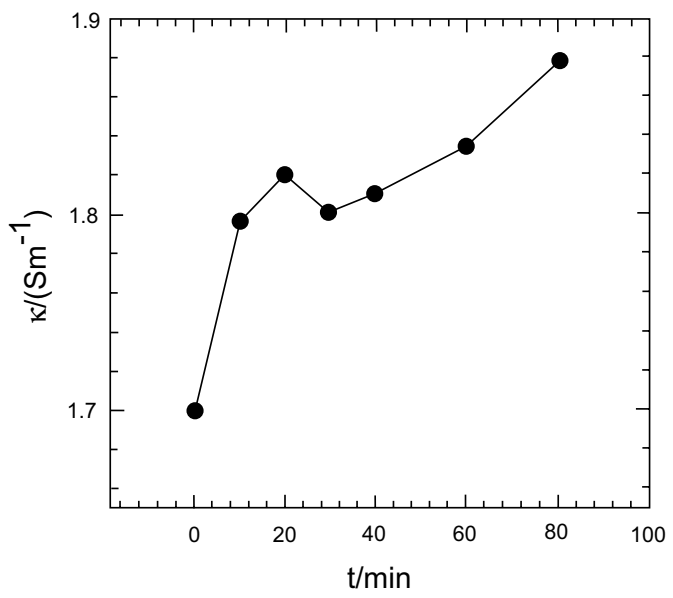

Figura 3. Variação da condutividade em função do tempo de eletrólise de um efluente de uma indústria liofilizadora de condimentos.

Observa-se na figura 4 que o potencial relacionado à corrente aplicada diminui à medida que o tempo de eletrólise aumenta. Todavia, entre 10 e $60 \mathrm{~min}$ de eletrólise, ocorreu uma estabilidade nos valores de potencial, a qual coincide com a estabilização dos valores de condutividade (vide Fig. 3). O decréscimo do potencial com o tempo de eletrólise ocorre em paralelo com o aumento da condutividade.

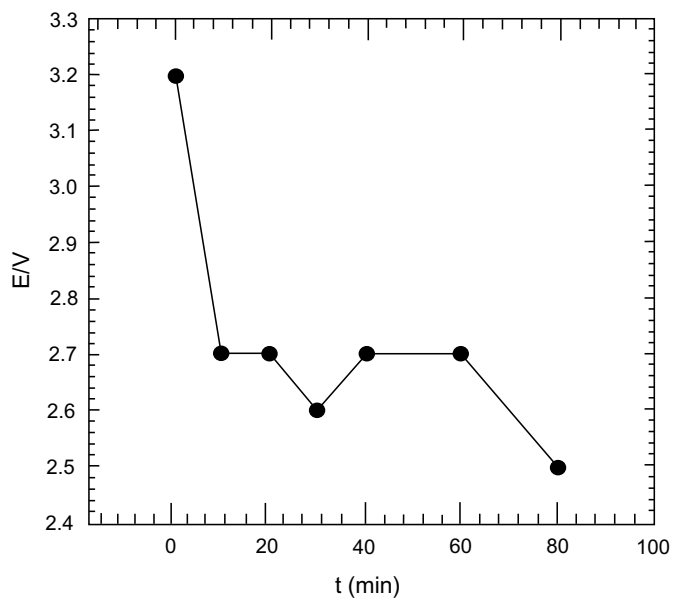

Figura 4. Potencial medido durante a eletrólise a corrente controlada de 4,00 A $\left(9,09 \mathrm{~A} \mathrm{~m}^{-2}\right)$ em função do tempo de eletrólise de um efluente de uma indústria liofilizadora de condimentos.

A DQO indica a quantidade de oxigênio que seria consumida através de reações químicas de oxidação dos diversos compostos orgânicos presentes, sem a intervenção de microrganismos; assim, ela fornece uma idéia, de maneira indireta, da quantidade de matéria orgânica presente no efluente eletrolisado. Conforme mostrado na figura 5, após $30 \mathrm{~min}$ de eletrólise, houve uma diminuição da DQO de cerca de $80 \%$. Esta acentuada redução no valor da DQO indica que a eletrólise é bastante eficiente na oxidação da matéria orgânica.

Com a oxidação, a matéria orgânica flocula rapidamente ao interagir com os íons ferro que são produzidos no anodo, 


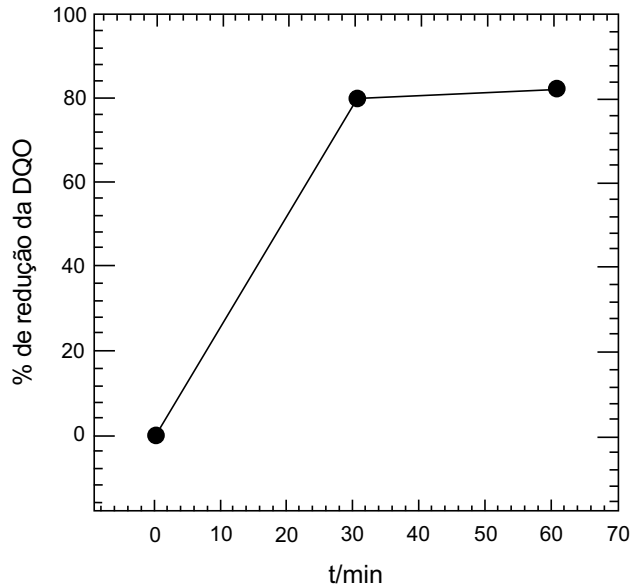

Figura 5. Porcentagem de redução da demanda química de oxigênio (DQO) em função do tempo de eletrólise de um efluente de uma indústria liofilizadora de condimentos.

aumentando, portanto, a quantidade de sólidos sedimentáveis. $\mathrm{O}$ efluente eletrolisado durante $85 \mathrm{~min}$ apresentou uma decantação, num cone de Imhoff de $1 \mathrm{~L}$ (após $1 \mathrm{~h}$ ), de 89,0 mL de sedimentos. Já no caso do efluente não eletrolisado, essa sedimentação foi de apenas $14,0 \mathrm{~mL}$. A metodologia para a realização da DQO não recomenda a presença de íons $\mathrm{Fe}^{2+}$, pois estes interferem no teste oxidando o reagente que é o dicromato de potássio. Entretanto, a amostra do resíduo eletrolisado para o teste de DQO foi altamente aerada (agitação vigorosa com agitador de pás), o que garantiu que ela contivesse somente íons na forma $\mathrm{Fe}^{3+}$ que não interferem no teste da DQO. O íon $\mathrm{Fe}^{2+}$, um redutor forte, oxida-se rapidamente durante a eletrólise do resíduo nessas condições.

Um outro parâmetro importante é a DBO, a qual indica a quantidade de oxigênio consumida durante a degradação bioquímica da matéria orgânica no efluente, bem como a oxidação de espécies nitrogenadas e de algumas espécies redutoras $\left(\mathrm{Fe}^{2+}\right.$, $\mathrm{S}^{2-}$ etc.). Conforme pode ser observado na figura $6 \mathrm{~A}$, a eletrólise do efluente também possibilitou um aumento nos valores da DBO.

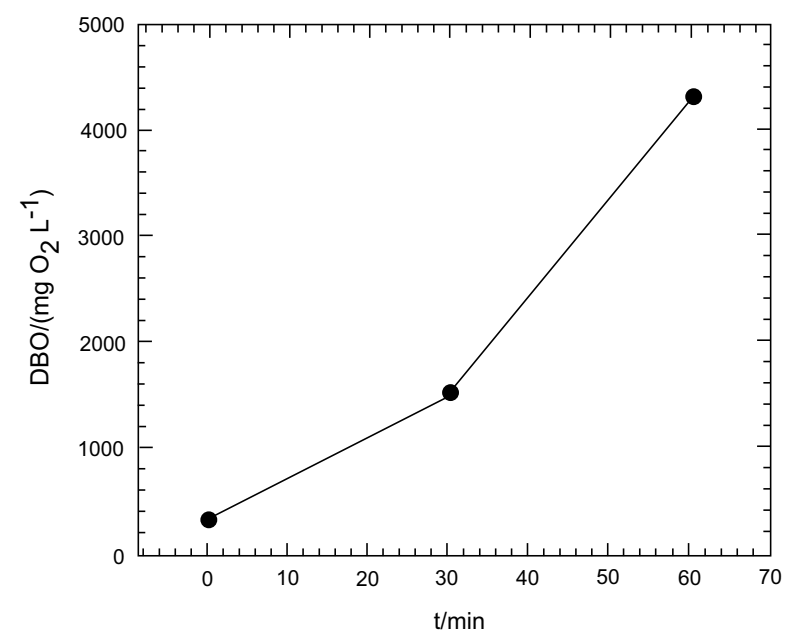

Figura 6. Demanda bioquímica de oxigênio (DBO) em função do tempo de eletrólise de um efluente de uma indústria liofilizadora de condimentos.

O valor de DBO é uma medida da quantidade de oxigênio assimilada pela oxidação microbiológica entre o início e o final de incubação por 5 dias a $20^{\circ} \mathrm{C}$. O aumento do valor de DBO relacionado com o tempo de aplicação da eletrólise indica a transformação e a quebra de moléculas recalcitrantes e/ou tóxicas presentes no resíduo, facilitando a sua posterior biodegradação. Assim, o maior consumo de oxigênio para o resíduo submetido ao maior tempo de eletrólise indica uma maior quantidade dessas espécies químicas menos tóxicas, tornando mais rápidos os processos de biodegradação. A figura 7 registra que a biotoxicidade aguda, determinada com Daphnia similis, diminuiu paralelamente ao aumento de oxigênio consumido no teste de DBO. Isto mais uma vez indica que a eletrólise facilita a biodegradabilidade do resíduo.

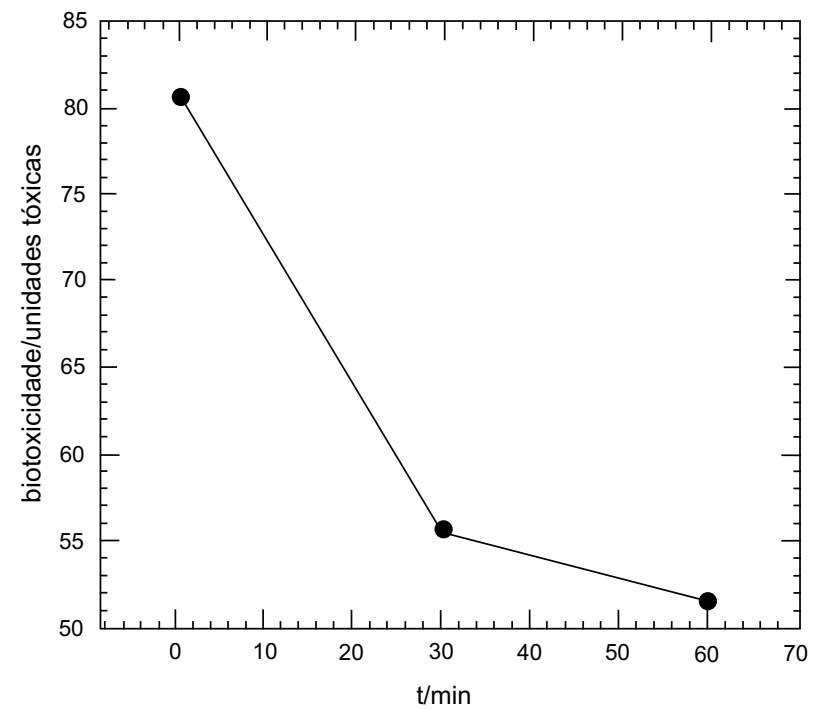

Figura 7. Biotoxicidade aguda (utilizando Daphnia similis), expressa em unidades tóxicas, para amostras de um efluente de uma indústria liofilizadora de condimentos eletrolisadas por distintos tempos.

Ao se realizar eletrólise de efluentes, também há interesse em se saber se esta promove a morte de microrganismos, especialmente bactérias. Os resultados do teste de contagem microbiana indicam que durante o processo de eletrólise ocorre sanitização do efluente em relação a bactérias. A figura 8 mostra que ocorreu uma redução porcentual de unidades formadoras de colônias de bactérias de cerca de $100 \%$ após 30 min de eletrólise. Neste trabalho o menor tempo escolhido para se realizar a contagem microbiana foi de $30 \mathrm{~min}$; entretanto, em outro trabalho ${ }^{28}$ constatou-se que a morte de quase $100 \%$ de microrganismos ocorreu em cerca de $10 \mathrm{~min}$ de eletrólise, em condições próximas daquelas realizadas neste trabalho.

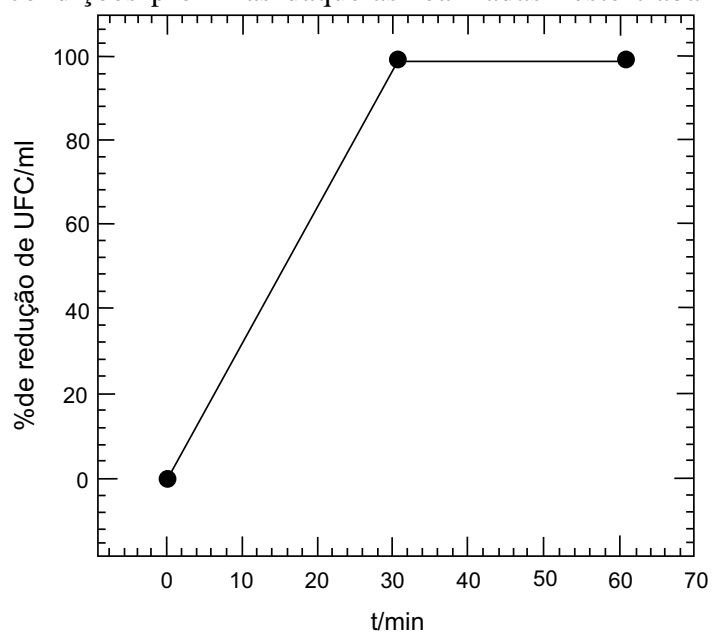

Figura 8. Porcentagem de redução de unidades formadoras de colônias bacterianas por mililitro do efluente em função do tempo de eletrólise de um efluente de uma indústria liofilizadora de condimentos. 
Propõe-se neste trabalho que a morte dos microrganismos bacterianos dá-se principalmente devido às propriedades redutoras do íon ferroso:

$\mathrm{Fe}^{2+}+$ microrganismo $\rightarrow$ microrganismo morto $+\mathrm{Fe}^{3+}$

A difusão do íon ferroso para o seio da solução permite que entre em contato com a parede celular do microrganismo. $\mathrm{O}$ íon $\mathrm{Fe}^{2+}$, ao entrar no citoplasma da célula, pode reduzir moléculas biologicamente ativas, induzindo rapidamente a morte do microrganismo. O fenômeno da morte dos microrganismos pela oxidação da parede celular na interface eletrodo/ solução é mais difícil devido ser esta região a parte mais protetora da célula. Há trabalhos ${ }^{29,30}$ que mostram que à medida que a parede celular do microrganismo torna-se mais espessa e resistente, como é o caso dos fungos em comparação com as bactérias, o número de células microbianas mortas diminui. Esta seleção na morte de microrganismos pela eletrólise pode ser utilizada como uma forma de descontaminar e sanitizar meios, ou seja, eliminar a população de bactérias sem interferir na população de fungos, por exemplo.

Finalmente, cabe tecer alguns comentários sobre o consumo de energia associado a esse processo eletrolítico. A energia elétrica consumida num tempo de $20 \mathrm{~min}$ de eletrólise (potencial médio de 2,7 V) é de somente cerca de $0,42 \mathrm{~kW} \mathrm{~h} \mathrm{~m}^{-3}$. Levando em conta o preço atual da energia elétrica, pode-se concluir que do ponto de vista do gasto de energia elétrica (cerca de $\mathrm{R} \$ 0,04 / \mathrm{m}^{3}$ ) o processo eletrolítico é bastante viável.

\section{CONCLUSÕES}

A utilização de eletrodos de aço inoxidável causa a liberação de íons de ferro no efluente, pela dissolução dos eletrodos durante a eletrólise. Essa liberação não acarreta problemas ambientais desde que a corrente, a colméia de eletrodos e o tempo de residência sejam dimensionados de forma adequada. Por outro lado, os íons $\mathrm{Fe}^{2+}$ inicialmente liberados causam a morte de microrganismos e, ao se oxidarem a $\mathrm{Fe}^{3+}$ contribuem para a floculação e sedimentação dos resíduos sólidos.

Ao mesmo tempo que a eletrólise promove a morte de microrganismos, a oxidação da matéria orgânica no efluente aumenta a possibilidade de sua biodegradabilidade. Isto permite que, após a eletrólise, haja um maior crescimento de microrganismos no efluente, indicado pelo aumento da DBO e pela redução da sua biotoxicidade.

Por outro lado, é baixo o consumo de energia elétrica pelo sistema de eletrólise constituído de eletrodos de aço inoxidável, o que não limita a utilização das eletrólises no tratamento de resíduos.

Finalmente, os resultados obtidos neste trabalho permitem concluir que o processo eletrolítico destroe as moléculas recalcitrantes, ou diminui os efeitos por elas causados, levando a um aumento da biodegradabilidade do resíduo poluidor. Assim, pode-se concluir que, para o tipo de resíduo estudado neste trabalho, um acoplamento do processo eletrolítico a um tratamento biológico convencional possibilitaria um tempo de retenção menor para a biodegradação, bem como uma maior eficiência na redução da matéria orgânica presente no resíduo através da diminuição da toxicidade. Esse acoplamento permitiria uma maior eficiência na biodegradação dos resíduos para os produtos finais, $\mathrm{CO}_{2}$ e água.

\section{AGRADECIMENTOS}

Agradece-se o apoio do CNPq - Conselho Nacional de Desenvolvimento Científico e Tecnológico para a realização desse trabalho.

\section{REFERÊNCIAS}

1. Bockris, J. O’M.; Nagy, Z.; Electrochemistry for Ecologists; Plenum; Nova Iorque, 1974.

2. Bockris, J. O'M. (Ed.); Electrochemistry of Cleaner Environments; Plenum; Nova Iorque, 1972.

3. Rajeshwar, K.; Ibanez, J. G.; Swain, G. M.; J. Appl. Electrochem. 1994, 24, 1077.

4. Brooman, E. W.; Fenton, J. M.; Hamel, C. (Eds.); Electrochemical Technology Applied to Environmental Problems; Electrochemical Society; Pennington, 1995.

5. Comninellis, C.; Electrochim. Acta 1994, 39, 857.

6. Steele, D. F.; Chemistry in Britain 1991, 29, 915.

7. Kaba, L.; Hitchens, G. D.; Bockris, J. O’M.; J. Electrochem. Soc. 1990, 137, 1341.

8. Bezerril, P.; Wiendl, W. G.; Revista DAE 1985, 45, 420.

9. ESTEC; Processo Eletrolítico - Tratamento de Esgotos; UNICAMP; Campinas, 1986.

10. CETESB; Diagnóstico da Situação Atual das Estações Eletrolíticas de Tratamento de Esgotos; Diretoria de Controle da Poluição e Gerência do Setor de Controle de Bacias Hidrográficas; São Paulo, 1989.

11. Marson, H. W.; The Engineer 1965, $n^{\circ}$ 2, 591.

12. Miller, H. C.; Knipe, W.; Electrochemical Treatment of Municipal Waste Water; Dept. of Health, Education and Welfare; Washington, 1965; p. 59.

13. Brito, S.; Imprensa Nacional 1943, 2, 305.

14. Wiendl, W. G.; Revista DAE, 1985, 45, 50.

15. Herer, D. O.; Woodard, F. E.; Tappi 1976, 59, 134.

16. Cenkin, V. E.; Belevtsev, A. N.; Effl. Water Treat. J. 1985, 25, 243.

17. Oehr, K.; J. Water Poll. Control Fed. 1978, 50, 286.

18. Chemtech 1996, 26 (4). [este número da revista é totalmente dedicado ao tema "Managing Hazardous Waste with Electricity"]

19. Genders, J. D.; Hartsough, D.; Hobbs, D. T.; J. Appl. Electrochem. 1996, 26, 1.

20. Tennakoon, C. L. K.; Bhardwaj, R. C.; Bockris, J. O’M.; J. Appl. Electrochem. 1996, 26, 18.

21. Genders, J. D.; Hartsough, D.; Hobbs, D. T.; J. Appl. Electrochem. 1996, 26, 1.

22. Marconi, P. F.; Meunier, V.; Vatistas, N.; J. Appl. Electrochem. 1996, 26, 693.

23. Kalu, E. E.; White, R. E.; Hobbs, D. T.; J. Electrochem. Soc. 1996, 143, 3094.

24. Ross, N. C.; Spackman, R. A.; Hitchman, M. L.; White, P. C.; J. Appl. Electrochem. 1997, 27, 51.

25. Clesceri, L. S.; Greenberg, A. E.; Trussell, R. R.; Franson, M. A. H. (Eds.); Standard Methods for the Examination of Water and Wastewater; $17^{\mathrm{a}}$ ed.; Amercian Public Health Association; Nova Iorque, 1989.

26. Soares, P. S.; Correa, M. J.; Silva Filho, E. A.; Angelis, D. F. de; Bidoia, E. D.; Livro de Resumos da $16^{a}$ Reunião Anual da Sociedade Brasileira de Química; Caxambu, 2529 de maio de 1993; resumo AB-18.

27. Bidoia, E. D.; Soares, P. S.; Angelis, D. F. de; Dalfré, I. A. B.; Silva, E. M.; Livro de Resumos do Congresso Brasileiro de Análise Ambiental; Rio Claro, 23-27 de maio de 1994; p. 60-61.

28. Bratfich, O. J.; Moraes, P. B.; Domingos, R. N.;Angelis, D. F. de; Bidoia, E. D.; Anais do II Simpósio de Iniciação Científica do Campus de Rio Claro da UNESP; Rio Claro, 28-29 de maio de 1996; p. 39-41.

29. Tokuda, H.; Nakanishi, K.; Biosci. Biotech. Biochem. 1995, 59, 753.

30. Nakasono, S.; Nakamura, N.; Sode, K.; Matsunaga, T.; Bioelectrochem. Bioenerg. 1992, 27, 191. 